\title{
Integrity evaluation concerning vibrations of a welded structure
}

\author{
Emilian Stanciu ${ }^{1,2}$, Codrin Nitescu ${ }^{1}$, Zeno-Iosif Praisach ${ }^{1,3}$, and Gilbert-Rainer Gillich ${ }^{1, *}$ \\ ${ }^{1}$ Universitatea "Eftimie Murgu" din Resita, P-ta Taian Vuia 1-4, 320085 Resita, Romania \\ ${ }^{2}$ Windkraft Simonsfeld RO S.R.L., Str. Sportului B 26, 320110 Resita, Romania \\ ${ }^{3}$ S.C. UCM Reşiţa S.A., Str. Golului Nr. 1, 320053 Resita, Romania, Romania
}

\begin{abstract}
In this paper, a predictive model that describes the structural behavior in the absence and presence of damage, and anticipates the modal parameter changes, is introduced for weld structures. Degradation of engineering structures in the welds or HAZ due to damage affects their safety by reducing the stiffeners of structural components. In this paper was considered the kinetic energy distribution which reflects the mass participation, and the modal strain energy distribution which take into consideration the stiffeners reduction. The relation is successfully proved against FEM simulation results.
\end{abstract}

\section{Introduction}

Structural integrity assessment of engineering structures by means of vibration-based techniques had become a growing attention in the last decades [1,2]. The relation between stiffness and mass changes and natural frequency changes, coupled with ease of measurement of the natural frequencies by using only a single sensor, was the impetus for using modal methods to identify damage [3]. Generally, in such procedures, the stiffness decrease due to damage is correlated with the natural frequency drop, in this way being found the damage location and severity [4-6]. The greatest success in the use of natural frequency shifts for damage identification, as evidenced by the number of published examples, is in small simple laboratory structures with only single damage locations [7]. For weld structures, this approach is not possible, since here a relevant mass increase is expected. In addition, physical-mechanical parameters in the weld area, especially in the fusion zone, can significantly differ from that of the base material. This makes involving of more complex models necessary.

This paper, continuing our research in damage assessment of simple and complex structures [8-10], introduces a predictive model that describes the weld structure dynamical behavior in the absence and presence of damage and anticipates the modal parameter changes. The specific but weld joint zones have associated finite elements with tailored parameters. Based on this theoretical model a mathematical relation linking the changes introduced by the weld joint and the modal parameter shifts is contrived.

\footnotetext{
* Corresponding author: gr.gillich@uem.ro
} 


\section{Weld beam behavioral model}

Let us consider a clamped-hinged prismatic steel beam, with the density $\rho=7850 \mathrm{~kg} / \mathrm{m}^{3}$, the Young modulus $E=2 * 10^{11} \mathrm{~N} / \mathrm{m}^{2}$ and Poisson coefficient $v=0.3$. The beam has the width $b=0.020 \mathrm{~mm}$ and the height $h=0.005 \mathrm{~mm}$, and the length $L=1 \mathrm{~m}$. The weld is located at distance $L_{I}$ taken from the left beam end, as shown in Fig. 1. The length of the weld in longitudinal beam direction is $L_{w}=20 \mathrm{~mm}$. From literature is known that the heat affected zone, denoted HAZ, can be divided into three zones, depicted in Fig. 2. Starting from the base plate, these are the intercritical zone, the fine-grained zone, and the coarse-grained zone. Each of these zones has different characteristics, as follows: the intercritical zone has lower values of hardness, strength, and resilience and higher values of plasticity properties, the finegrained zone has higher values of hardness and strength and the coarse-grained zone has increased mass density and good corrosion resistance. Due to its shape, see Fig. 3, the weld height is bigger than the beam thickness.



Fig. 1. The clamped-hinged beam in welded construction.

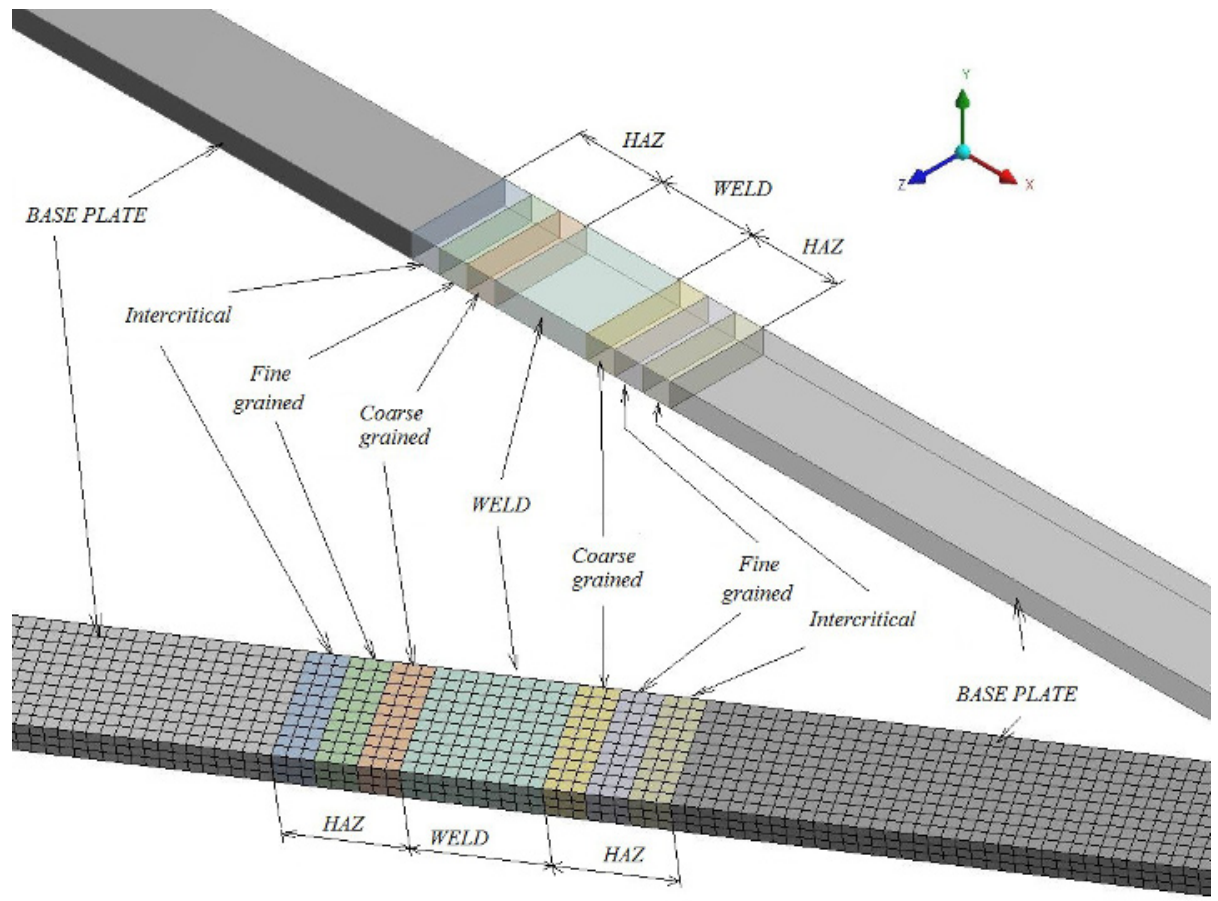

Fig. 2. 3D model and meshing of the model of a welded structure. 

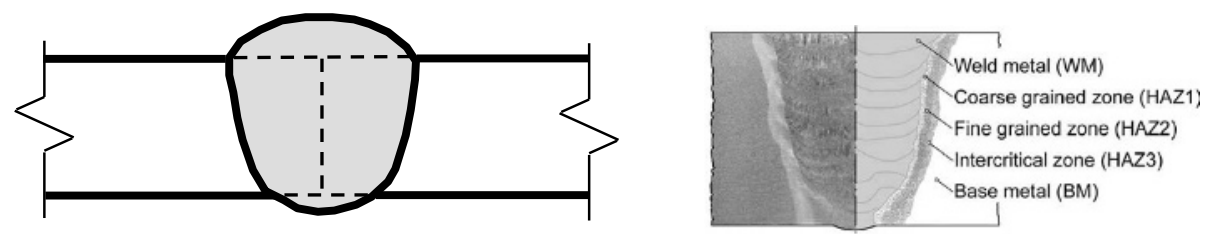

Fig. 3. Shape of weld (left image) and specific zones of the weld structure (right image).

For a clamped-hinged beam, the frequency equation is according to eq. (1) and the bending vibration mode shape is defined in eq. (2).

$$
\begin{gathered}
\tanh \alpha_{n}-\tan \alpha_{n}=0 \\
W(x)=D\left\{\frac{\cos \alpha_{n}+\cosh \alpha_{n}}{\sin \alpha_{n}+\sinh \alpha_{n}}\left[\sin \left(\alpha_{n} x\right)-\sinh \left(\alpha_{n} x\right)\right]-\cos \left(\alpha_{n} x\right)+\cosh \left(\alpha_{n} x\right)\right\}
\end{gathered}
$$

where $\alpha$ is the dimensionless wave number and $D=0.5$ is an integration constant, that get the value 0.5 to normalize the mode shape.

To simplify the analytic model, the weld in Fig. 3 will be considered with the same height as the beam, see Fig. 1 and 2. Thus, the weld density has been artificially increased in order not to affect the real weld beam mass. Finally, the resulting model is a welded beam with a constant cross-sectional area and different mass densities, one for the base plate and one for the weld.

Starting from kinetic energy conservation [11] we can write the equivalent mass contribution for each segment of the weld beam:

$$
\left\{\begin{array}{l}
m_{L_{1}}{ }^{e q}=\bar{m}_{b 1} L \int_{0}^{L_{1}}\left[W_{n}(x)\right]^{2} d x \\
m_{L_{w}}{ }^{e q}=\bar{m}_{w} L \int_{L_{1}}^{L_{1}+L_{w}}\left[W_{n}(x)\right]^{2} d x \\
m_{L_{2}}{ }^{e q}=\bar{m}_{b 2} \int_{L_{1}+L_{w}}^{L-L_{1}-L_{w}}\left[W_{n}(x)\right]^{2} d x \\
m_{L}{ }^{e q}=\bar{m} L \int_{0}^{L}\left[W_{n}(x)\right]^{2} d x=0.25 \bar{m} L
\end{array}\right.
$$

where $m_{L_{1}}{ }^{e q}, m_{L_{w}}{ }^{e q}, m_{L_{2}}{ }^{e q}, m_{L}{ }^{e q}$ is the equivalent specific mass corresponding to the $n^{\text {th }}$ bending vibration mode for the left beam segment with length $L_{l}$, for the right beam segment with length $L_{2}$, for the weld $L_{w}$, respectively for or whole beam length $L$, and $\bar{m}_{b 1}, \bar{m}_{b 1}$, $\bar{m}_{b 1}, \bar{m}_{b 1}$ are the specific masses for respective lengths.

For $\alpha_{n}$ derived from eq. (1) and taking in consideration eq. (3), the natural frequencies of the weld beam can be calculated from:

$$
f_{i}=\frac{\alpha_{i}^{2}}{2 \pi} \sqrt{\frac{E I_{z}}{\bar{m}_{b} L^{4}}}=\frac{\alpha_{i}^{2}}{2 \pi} \sqrt{\frac{E I_{z}}{4 m_{n}{ }^{e c h} L^{3}}}=\frac{\alpha_{i}^{2}}{2 \pi} \sqrt{\frac{E I_{z}}{4\left(m_{L_{1}}{ }^{e c h}+m_{L_{c s}}{ }^{e c h}+m_{L_{2}}{ }^{e c h}\right) L^{3}}}
$$

If a damage located in the middle of the weld $\left(L_{w} / 2\right)$ and having the depth $a=1 \mathrm{~mm}$ respectively width $L_{d 2}-L_{d l}=1 \mathrm{~mm}$ is considered, see Fig. 1, the stiffness in this section is 
modified. The moment of inertia will decrease from $I=b h^{3} / 12$ to $I_{D}=b(h-a)^{3} / 12$ and taking into consideration the ratio between loss energy distribution and total energy distribution along the beam, we have:

$$
\frac{\bar{U}_{i D}(x)}{\bar{U}_{i}}=\frac{\frac{1}{2 E I} \int_{0}^{L}\left[\frac{d^{2} W(x)}{d x^{2}}\right]^{2} d x-\frac{I-I_{D}}{I} \frac{1}{2 E I} \int_{L_{d 1}}^{L_{d 2}}\left[\frac{d^{2} W(x)}{d x^{2}}\right]^{2} d x}{\frac{1}{2 E I} \int_{0}^{L}\left[\frac{d^{2} W(x)}{d x^{2}}\right]^{2} d x}
$$

thus

$$
\frac{\bar{U}_{i D}(x)}{\bar{U}_{i}}=1-4 \frac{I-I_{D}}{I} \int_{L_{d 1}}^{L_{d 2}}\left[\frac{d^{2} W(x)}{d x^{2}}\right]^{2} d x
$$

It is known that the ratio of the natural frequencies between damaged and healthy beam lead us to expression:

$$
\frac{f_{i D}}{f_{i}}=\sqrt{\frac{\bar{U}_{i D}(x)}{\bar{U}_{i}}}=\sqrt{1-4 \frac{I-I_{D}}{I} \int_{L_{d 1}}^{L_{d 2}}\left(\frac{d^{2} W(x)}{d x^{2}}\right)^{2} d x}
$$

and finally, the relationship which permit us to calculate the natural frequency for a welded beam with damage:

$$
f_{d i}=f_{i} \sqrt{1-4 \frac{I-I_{d}}{I} \int_{L_{d 1}}^{L_{d 2}}\left(\frac{d^{2} W(x)}{d x^{2}}\right)^{2} d x}
$$

For the first six vibration modes, the results are presented in tables 1, 2 and 3.

\section{Numerical investigations}

The investigations by finite element method were performed via ANSYS software, by using the modal analysis module. The medium size of the mesh element is $2 \mathrm{~mm}$, as shown in Fig. 2. For the HAZ were used following parameters:

- intercritical zone length of $6 \mathrm{~mm}$ with mass density of $\rho_{i c}=7700 \mathrm{~kg} / \mathrm{m}^{3}$, and Young modulus $E_{i c}=2.0 * 10^{11} \mathrm{~N} / \mathrm{m}^{2}$;

- fine grained zone of $6 \mathrm{~mm}$ with mass density of $\rho_{f g}=7850 \mathrm{~kg} / \mathrm{m}^{3}$, and Young modulus $E_{f g}=2.1 * 10^{11} \mathrm{~N} / \mathrm{m}^{2}$

- coarse grained zone of $6 \mathrm{~mm}$ with mass density of $\rho_{c g}=8000 \mathrm{~kg} / \mathrm{m}^{3}$, and Young modulus $E_{c g}=2.05 * 10^{11} \mathrm{~N} / \mathrm{m}^{2}$.

For the weld was considered an artificially increased mass density of $\rho_{w}=10990 \mathrm{~kg} / \mathrm{m}^{3}$ corresponding for a weld with $2 \mathrm{~mm}$ over beam height and Young modulus $E_{w}=2.0^{*} 10^{11}$ $\mathrm{N} / \mathrm{m}^{2}$; and for the base plate the mass density of $\rho_{b p}=7850 \mathrm{~kg} / \mathrm{m}^{3}$ and Young modulus $E_{b p}=2.0 * 10^{11} \mathrm{~N} / \mathrm{m}^{2}$.

The weld is stepwise replaced from $L_{1}+L_{w} / 2=0.5 L$ to $L_{1}+L_{w} / 2=0.1 L$. For the first six vibration modes, the results attained from numerical investigations are presented in tables 1 to 3 . In these tables, the natural frequency values obtained from the analytic evaluation by employing eq. (4) and (8) are also presented. In Figure 4 the results are presented in graphical form, making them easily comparable; the fit is obvious. 
Table 1. Natural frequencies for welded beam with damage at $L_{1}+L_{w} / 2=0.5 L$ and $L_{I}+L_{w} / 2=0.4 L$

\begin{tabular}{|l|c|c|c|c|c|c|c|}
\hline \multirow{2}{*}{$\boldsymbol{i}$} & $\boldsymbol{\alpha}$ & \multicolumn{3}{|c|}{$\boldsymbol{L}_{\boldsymbol{1}}+\boldsymbol{L}_{\boldsymbol{w}} / \mathbf{2}=\mathbf{0 . 5} \boldsymbol{L}$} & \multicolumn{3}{c|}{$\boldsymbol{L}_{\boldsymbol{1}}+\boldsymbol{L}_{\boldsymbol{w}} / \mathbf{2}=\mathbf{0 . 4 L} \boldsymbol{L}$} \\
\cline { 3 - 8 } & $\boldsymbol{f}_{\text {di }}[\mathrm{Hz}]$ & $\boldsymbol{f}_{\text {FEM }}[\mathrm{Hz}]$ & $\begin{array}{c}\text { Deviation } \\
{[\%]}\end{array}$ & $\boldsymbol{f}_{\boldsymbol{d} i \boldsymbol{H}}[\mathrm{Hz}]$ & $\boldsymbol{f}_{F E M}[\mathrm{~Hz}]$ & $\begin{array}{c}\text { Deviation } \\
{[\%]}\end{array}$ \\
\hline 1 & 3.9266 & 17.8658 & 17.7330 & 0.74 & 17.8721 & 17.7898 & 0.46 \\
\hline 2 & 7.0686 & 57.9280 & 57.9031 & 0.04 & 57.8937 & 57.5068 & 0.67 \\
\hline 3 & 10.2102 & 120.7760 & 119.9339 & 0.70 & 120.8743 & 120.9362 & 0.05 \\
\hline 4 & 13.3518 & 206.6783 & 206.4900 & 0.09 & 206.5049 & 204.7770 & 0.84 \\
\hline 5 & 16.4934 & 315.1636 & 312.7717 & 0.76 & 315.3611 & 314.7990 & 0.18 \\
\hline 6 & 19.6350 & 446.9689 & 446.2430 & 0.16 & 446.8095 & 444.6690 & 0.48 \\
\hline
\end{tabular}

Table 2. Natural frequencies for welded beam with damage at $L_{1}+L_{w} / 2=0.3 L$ and $L_{1}+L_{w} / 2=0.2 L$

\begin{tabular}{|l|c|c|c|c|c|c|c|}
\hline \multirow{2}{*}{$\boldsymbol{i}$} & $\boldsymbol{\alpha}$ & $\boldsymbol{f}_{\text {di }}[\mathbf{H z}]$ & $\boldsymbol{f}_{\text {FEM }}[\mathbf{H z}]$ & $\begin{array}{c}\text { Deviation } \\
{[\%]}\end{array}$ & $\boldsymbol{f}_{\boldsymbol{d i}}[\mathrm{Hz}]$ & $\boldsymbol{f}_{\text {FEM }}[\mathbf{H z}]$ & $\begin{array}{c}\text { Deviation } \\
{[\%]}\end{array}$ \\
\hline 1 & 3.9266 & 17.8773 & 17.8489 & 0.16 & 17.8759 & 17.8743 & 0.01 \\
\hline 2 & 7.0686 & 57.8898 & 57.3852 & 0.87 & 57.9254 & 57.7056 & 0.38 \\
\hline 3 & 10.2102 & 120.8137 & 120.2281 & 0.48 & 120.7884 & 119.7365 & 0.87 \\
\hline 4 & 13.3518 & 206.7063 & 206.7814 & 0.04 & 206.5397 & 204.8341 & 0.83 \\
\hline 5 & 16.4934 & 315.1943 & 313.1465 & 0.65 & 315.3269 & 314.3157 & 0.32 \\
\hline 6 & 19.6350 & 446.6495 & 443.1368 & 0.79 & 447.0328 & 446.8960 & 0.03 \\
\hline
\end{tabular}

Table 3. Natural frequencies for welded beam with damage at $L_{1}+L_{w} / 2=0.1 L$

\begin{tabular}{|l|c|c|c|c|}
\hline \multirow{2}{*}{$\boldsymbol{i}$} & \multirow{\alpha}{*}{$\boldsymbol{\alpha}$} & \multicolumn{3}{|c|}{$\boldsymbol{L}_{\boldsymbol{1}}+\boldsymbol{L}_{\boldsymbol{w}} / \mathbf{2}=\mathbf{0 . 1 L}$} \\
\cline { 3 - 5 } & & $\boldsymbol{f}_{\text {di }}[\mathrm{Hz}]$ & $\boldsymbol{f}_{\text {FEM }}[\mathbf{H z}]$ & $\begin{array}{c}\text { Deviation } \\
{[\%]}\end{array}$ \\
\hline 1 & 3.9266 & 17.8646 & 17.8494 & 0.09 \\
\hline 2 & 7.0686 & 57.9249 & 57.9152 & 0.02 \\
\hline 3 & 10.2102 & 120.8776 & 120.7347 & 0.12 \\
\hline 4 & 13.3518 & 206.6846 & 205.9404 & 0.36 \\
\hline 5 & 16.4934 & 315.3033 & 313.1942 & 0.67 \\
\hline 6 & 19.6350 & 446.7288 & 442.5647 & 0.93 \\
\hline
\end{tabular}

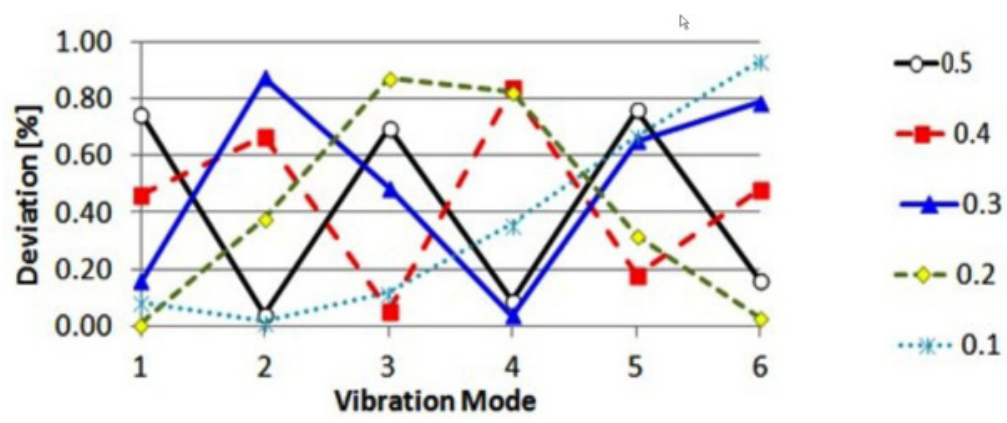

Fig. 4. Deviation of the natural frequency values attained analytically and from numerical simulations for a welded beam with damage. 


\section{Conclusions}

The paper introduces a mathematical model which allows predicting the vibrational behavior of weld structures with damage. It takes into account the mass increase, due to weld and the changes of mass density and elasticity occurred in the HAZ Results obtained by using this relation were tested against FEM simulation results. Analyzing the results one can observe that natural frequency deviation between analytical approach and numerical investigation, for the first six vibration mode, is less than $1 \%$. This qualifies the proposed relation for predicting frequency changes due to damage and finds its application in damage detection procedures.

Next approaches will take into consideration other types of defects occurred in welding processes, and will be extended to real structures.

\section{References}

1. G.-R. Gillich, Z. Praisach, D.M. Onchis, Proceedings of the International Conference on Engineering Mechanics, Structures, Engineering Geology, International Conference on Geography and Geology, 204-209 (2010)

2. G.-R. Gillich, Z.-I. Praisach, M. Abdel Wahab, N. Gillich, I.C. Mituletu, C. Nitescu, Free Vibration of a Perfectly Clamped-Free Beam with Stepwise Eccentric Distributed Masses, Shock and Vibration, article 2086274 (2016)

3. J.S. Sakellariou, S.D. Fassois, Journal of Sound and Vibration, 297(3-5), 1048-1067 (2006)

4. Y. Hui, S.S. Law, C.J. Ku, Journal of Sound and Vibration, 389, 168-182 (2017)

5. G.R. Gillich, M. Abdel Wahab, Z.I. Praisach, J.L. Ntakpe, Proceedings of ISMA 2014, 485-498 (2014)

6. M. Chandrashekhar, R. Ganguli, Mechanical Systems and Signal Processing, 75, 75-93 (2016)

7. G.-R. Gillich, E.D. Birdeanu, N. Gillich, D. Amariei, V. Iancu, C.S. Jurcau, Annals of DAAAM and Proceedings of the International DAAAM Symposium, 623-624 (2011)

8. G.-R. Gillich, N.M.M. Maia, I.-C. Mituletu, Z.-I. Praisach, M. Tufoi, I. Negru, Latin American Journal of Solids and Structures, 12(12), 2311-2329 (2015)

9. Z. Praisach, G.-R. Gillich, D.E. Birdeanu, Proceedings of the International Conference on Engineering Mechanics, Structures, Engineering Geology, International Conference on Geography and Geology,, 2014-2019 (2010)

10. G.-R. Gillich, Z.-I. Praisach, I. Negru, Materiale Plastice, 49 (3), 186-191 (2012)

11. G.-R. Gillich, Z.I. Praisach, V. Iancu, H. Furdui, I. Negru, Strojniski Vestnik/Journal of Mechanical Engineering, 61 (12), 721-730 (2015) 